\title{
Subcutaneous human dirofilariasis
}

\author{
Elizabeth Joseph • Anna Matthai - Latha K. Abraham • \\ Sunitha Thomas
}

Received: 12 February 2011/Accepted: 5 May 2011/Published online: 20 May 2011

(C) Indian Society for Parasitology 2011

\begin{abstract}
Subcutaneous human dirofilariasis is caused by the zoonotic filariae Dirofilaria repens. The frequency of reports is increasing in literature during the last few years and is considered by some authors as an emerging zoonosis. Here we report 21 cases of subcutaneous dirofilariasis, which were encountered over a period of 8 years. None of these cases were associated with peripheral eosinophilia. Since these lesions can mimic benign and malignant tumors, it is important to consider this as a differential diagnosis of subcutaneous nodules especially in an endemic area. In this report we would like to emphasize the importance of studying multiple deeper levels in suspected cases of parasitic granuloma to demonstrate the parasite.
\end{abstract}

Keywords Human dirofilariasis - Subcutaneous ·

Face $\cdot$ Chest $\cdot$ Abdominal wall $\cdot$ Scrotum

\section{Introduction}

The human beings are infected with species of filariasis normally found in animals. Among these zoonotic infections, the commonest is that reported due to Dirofilaria species-Dirofilaria repens or Dirofilaria imitis. The lung lesions are caused by Dirofilaria imitis while the subcutaneous lesion is caused mostly by Dirofilaria repens. It is

E. Joseph · A. Matthai - L. K. Abraham - S. Thomas Department of Pathology, Malankara Orthodox Syrian Church Medical College, Kolenchery, Ernakulam District,

Kerala 682 311, India

E. Joseph $(\varangle)$

Department of Pathology, Al Sabah Hospital, Post Box 4078,

Safat 13041, Kuwait

e-mail: elzakjohn@gmail.com transmitted by the bite of mosquito especially of anopheles, aedes and culex species. The review of literature revealed 800 cases distributed worldwide (Munro et al. 1999; Nadgir et al. 2001; Vikas Gautam et al. 2002). Majority of cases are reported from southern and eastern Europe, Srilanka, Italy, France, Greece and Spain. The reported cases from India are limited and most of the published cases are ocular dirofilariasis (Nadgir et al. 2001; Vikas Gautam et al. 2002; Sekhar et al. 2000). Here we report a series of 21 cases of dirofilariasis which presented as subcutaneous nodule mostly over exposed areas. To the best of our knowledge, this is the first and largest series of subcutaneous dirofilariasis from Kerala, the southernmost part of India.

\section{Materials and methods}

This study included the excision biopsy specimens received in the Department of Pathology, Malankara Orthodox Syrian Church Medical College, Kolenchery, Ernakulam, Kerala during March 2002 to December 2009. The clinical details were retrieved from the case files.

Fine needle aspiration cytology (FNAC) was attempted in two cases. Excision biopsy was done in all cases and the postoperative period was uneventful. In all cases the entire tissue was processed using routine technique and sections were examined using haematoxylin and eosin stain. Multiple deeper levels were studied in those cases where the parasite could not be identified in the initial sections.

\section{Results}

The clinical details are given in Table 1. The age of the patients ranged between 1 and 65 years. Sixty-two 
Table 1 Clinical details of patients

\begin{tabular}{|c|c|c|c|c|}
\hline Sl No: & Age/sex & Site & Duration & Clinical diagnosis \\
\hline 1 & $53 / \mathrm{F}$ & Infratemporal region & 2 weeks & ? Tumour \\
\hline 2 & $60 / \mathrm{F}$ & Lower chest & 3 weeks & Neurofibroma \\
\hline 3 & $45 / \mathrm{F}$ & Cheek & 1 months & ? Tumour/? Lipoma \\
\hline 4 & $19 / \mathrm{F}$ & Arm & 2 months & Sebaceous cyst \\
\hline 5 & $1 / \mathrm{M}$ & Left hypochondrium & 11 days & Lipoma/Sebaceous cyst \\
\hline 6 & $27 / \mathrm{M}$ & Medial canthus & 3 weeks & Infected Sebaceous cyst/?Parasitic cyst \\
\hline 7 & $65 / \mathrm{M}$ & Left flank & 4 days & Infected sebaceous cyst \\
\hline 8 & $28 / \mathrm{F}$ & Right thigh & 1 year & Filarial cyst \\
\hline 9 & $48 / \mathrm{M}$ & Neck & 1 month & Cervical node \\
\hline 10 & $34 / F$ & Abdominal wall & 2 weeks & Filarial nodule \\
\hline 11 & $35 / \mathrm{F}$ & Arm & 3 weeks & Inflammatory swelling \\
\hline 12 & $38 / \mathrm{F}$ & Rt inguinal region & 1 year & $\begin{array}{l}\text { ? Lymph node } \\
\text { ? Parasite }\end{array}$ \\
\hline 13 & $22 / \mathrm{F}$ & Left arm & 5 days & Thrombophlebitis/Fat necrosis \\
\hline 14 & $14 / \mathrm{M}$ & Lt axilla & 1 month & Tuberculous lymphadenitis \\
\hline 15 & $25 / \mathrm{M}$ & Lt chest wall & 2 months & Neurofibroma/Lipoma \\
\hline 16 & $56 / \mathrm{F}$ & Anterior aspect neck & 3 weeks & ? Thyroid nodule \\
\hline 17 & $50 / \mathrm{M}$ & Chest wall & 10 days & Infectd sebaceous cyst/Neurofibroma \\
\hline 18 & $10 / \mathrm{F}$ & Left nasolabial fold & 2 months & ? Parasitic cyst? Lymph node \\
\hline 19 & $39 / \mathrm{F}$ & Parotid region & 2 months & Lymph node \\
\hline 20 & $1 / \mathrm{M}$ & Epididymal cyst & 1 month & Filarial cyst \\
\hline 21 & $24 / \mathrm{F}$ & Infraorbital & 2 months & Neurofibroma \\
\hline
\end{tabular}

percentage of cases occurred in females and thirty eight percentage occurred in males. The usual site was the upper half of the body. The duration of symptoms varied between 4 days to 1 year. Clinically the possibility of parasitic cyst was considered in six cases and in other cases the differential diagnosis included benign and inflammatory conditions. Laboratory investigations failed to reveal eosinophilia in any of these cases.

In one case FNAC yielded only few eosinophils but in the second case, a thread like thin slender parasite could be identified in a background eosinophils and multinucleated giant cells.

The size of the lesions ranged from 0.75 to $1.5 \mathrm{~cm}$. The nodules revealed cystic appearance in two cases and intact parasite could be identified in both these cases. The cross section of the parasite showed thick cuticle with prominent muscle layer. The body cavity showed cross section of genital tubules suggestive of Dirofilaria repens (Fig. 1). In other cases there was a thick fibrotic cyst wall densely infiltrated with lymphocytes, plasma cells, eosinophils and foreign body type giant cells. The center of the cyst contained cross section of the parasite (Fig. 2) suggestive of D. repens. In four cases the initial sections failed to reveal the parasite. Then multiple serial deeper sections were studied which showed partly degenerated parasite with thick hyalinised cuticle suggestive of Dirofilaria species.

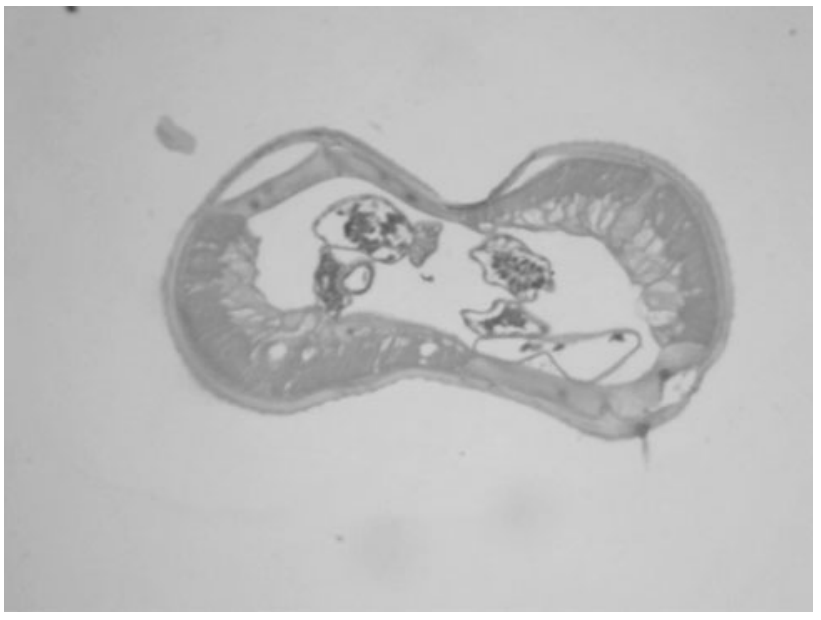

Fig. 1 Photomicrograph showing cross section of Dirofilaria. Note the thick cuticle, muscle layer and body cavity (haematoxylin and eosin stain $40 \times$ )

\section{Discussion}

Human subcutaneous dirofilariasis is caused by the nematode of the species Dirofilaria repens (D. repens). The usual definitive host of Dirofilaria repens is the dog, although cats, wolves, coyotes, foxes, muskrats, and sea lions may act as suitable hosts and reservoirs. Mosquitoes 


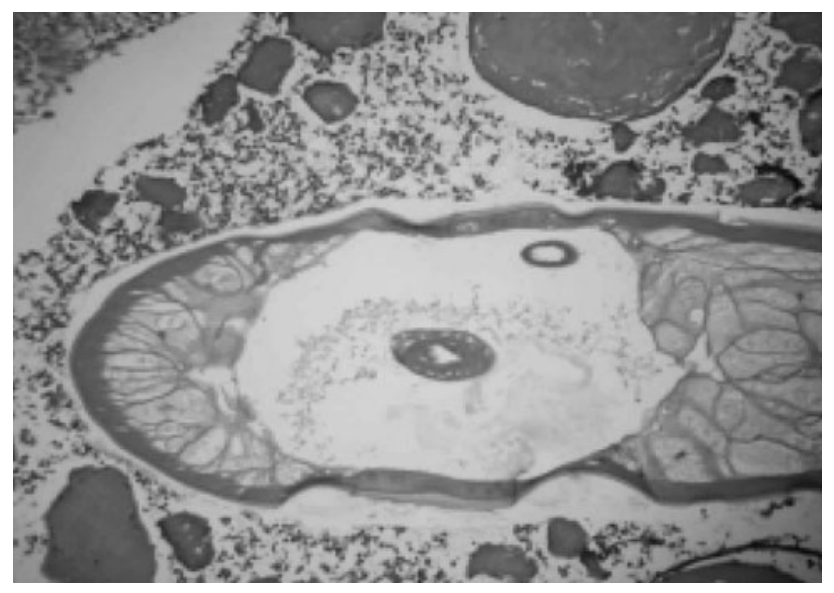

Fig. 2 Photomicrograph showing cross section of Dirofilaria surrounded by inflammatory cells (haematoxylin and eosin $40 \times$ )

of the genera Aedes, Anopheles, and Culex are suitable intermediate hosts and vectors. Some species of fleas, lice, and ticks may also act as vectors. The adults of D. repens reside in the subcutaneous tissues of the dogs and cats. The female worm releases microfilariae into the circulation daily, which is ingested by the mosquitoes in a blood meal (Orihel 1969). The humans are the dead end hosts of Dirofilaria since adult worms do not reach maturity in the skin. Most infective larvae injected into humans are thought to perish. So microfilaremia will not occur in humans.

The first documented report of human dirofilariasis dates back to the report of Addario in 1885 from Italy. Since then about 800 cases are reported worldwide. The reports of dirofilariasis are increasing nowadays and many authors have considered this as an emerging zoonosis. (Pampiglione et al. 2001) Most of the reported cases are from Southern and Eastern Europe, Sri Lanka, Italy, France, Greece and Spain. Pampiglone has reported the largest series of 60 cases from Italy in 2001. The first case of subcutaneous dirofilariasis from Kerala is reported by Senthivel and Pillai (1999) in a lady from Palakkad district and the subsequent reports are mostly case reports. To the best of our knowledge this is the first and largest series of subcutaneous dirofilariasis from Kerala.

The most important risk factors regarding human infections are mosquito density, warm climate with extended mosquito breeding season, outdoor human activities and the abundance of microfilaremic dogs. The reported incidence of microfilariasis in dogs from Ernakulam, Kerala is $7.59 \%$ (Lucy Sabu et al. 2005). Although all environmental conditions are prevalent in Kerala, the incidence of human dirofilariasis is low. The possible explanation being many of them remains undiagnosed or unpublished.

Infections in humans are usually asymptomatic except in cases where the worm enters the conjunctiva. Occasionally inflammatory changes can occur in subcutaneous nodules (Ratnatunga and Wijesundera 1999). Two of our cases had a similar presentation but the other cases were asymptomatic.

In this study, the site of the lesion is predominantly over the face or anterior chest wall. This is comparable to the earlier reports (Pampiglione et al. 2001; 1995). This may be explained by the biting habit of mosquito over exposed areas. Dirofilariasis has also been reported in deeper tissues like omentum. Pampiglione et al. has explained this as migration of the parasite to its final position by slow migration through soft tissues until it was blocked by the host's defence mechanism.

The youngest age reported in this series is about 1 year. Similar cases of human dirofilariasis in children have been reported from Sri Lanka (Dissanaike and De Abeyewickreme 1997). The clinical features of our cases are similar to the cases reported earlier. Though the number of cases is small in this series, there is a slight female preponderance and this is also in accordance with earlier reports.

As evident in this report, subcutaneous dirofilariasis can mimic various benign and malignant lesions. Breast nodules due to $D$. repens infection may be misdiagnosed as potential malignancy. Hence it is important that clinicians should be familiar with this entity and include it as a differential diagnosis of subcutaneous nodules.

The diagnosis of dirofilariasis can be made with certainty only after excision biopsy and the species identification is based on microscopic features of the parasite. So it is important that pathologists too must be familiar with the histopathological features of the parasite. The precise identification of species may be achieved with DNA analysis based on polymerase chain reaction, but the large number of specific probes limits the usefulness of this method (Favia et al. 1998).

In summary, dirofilariasis should be included in the differential diagnosis of subcutaneous nodules especially in an endemic area. It is also recommended that multiple serial sections should be studied in suspected cases to reveal the parasite.

Acknowledgments We the authors are thankful to the Secretary and Dean of our institution for permitting us to publish this paper. We are also thankful to all the staff members of the various surgical departments for providing the material for this study

Conflict of interest None to declare.

\section{References}

Dissanaike AS, De Abeyewickreme WS, Wijesundera M et al (1997) Human dirofilariasis caused by Dirofilaria (nochtiella) repens in Sri Lanka. Parassitologia 39:375-382 
Favia G, Lanfrancotti A, della Torre A et al (1998) Advances in the identification of Dirofilaria repens and Dirofilaria imitis by a PCR-based approach. Parassitologia 40:401-402

Gautam V, Rustagi IM, Singh S et al (2002) Subconjunctival infection with Dirofilaria repens. Jpn J Infect Dis 52:47-48

Munro A, Genchi C, Cordero M, Simon F (1999) Human dirofilariasis in the European Union. Parasitol Today 15:386-389

Nadgir S, Tallur SS, Mangoli V et al (2001) Sunconjunctival dirofilariasis in India. Southeast Asian J Trop Med Public Health 32(2):244-246

Orihel TC (1969) Dirofilaria corynodes (Linstow, 1899): morphology and life history. J Parasitol 55:94-103

Pampiglione S, Canestri Trotti G, Rivasi F (1995) Human Dirofilariasis due to Dirofilaria (nochtiella) repens; a review of world literature. Parassitologia 37:149-193
Pampiglione S, Rivasi F, Angeli G et al (2001) Dirofilariasis due to Dirofilaria repens in Italy, an emergent zoonosis: report of 60 new cases. Histopathology 38:34-354

Ratnatunga N, Wijesundera MS (1999) Histopathological diagnosis of subcutaneous Dirofilaria repens infection in humans. Southeast Asian J Trop Med Public Health 30:375-378

Sabu L, Devada K, Subramanian H (2005) Dirofilariosis in dogs and humans in Kerala. Indian J Med Res 121:691-693

Sekhar HS, Srinivas H, Battu R et al (2000) Human ocular dirofilariasis in Kerala, Southern India. Indian J Pathol Microbiol 43:77-79

Senthivel K, Pillai KM (1999) A case of subcutaneous dirofilariasis in a woman in Kerala. Indian Vet J 76:263-264 